\title{
Enhanced Light Scattering with Energy Downshifting Using 16 nm Indium Nitride Nanoparticles for Improved Thin-film a-Si N-i-P Solar Cells \\ Farsad Imtiaz Chowdhury ${ }^{\mathrm{a}}$, Kazi Islam ${ }^{\mathrm{a}}$, Sabri Alkis ${ }^{\mathrm{b}}$, Bülend Ortaç ${ }^{\mathrm{b}}$, Mustafa Alevli ${ }^{\mathrm{c}}$, Nikolaus Dietz ${ }^{\mathrm{d}}$, Ali K. Okyay ${ }^{\mathrm{b}, \mathrm{e}}$, and Ammar Nayfeh ${ }^{\mathrm{a}}$ \\ ${ }^{a}$ Institute Center for Future Energy Systems (iFES), Department of Electrical Engineering and Computer Science (EECS), Masdar Institute of Science and Technology, Abu Dhabi, United Arab Emirates \\ ${ }^{\mathrm{b}}$ UNAM - National Nanotechnology Research Center and Institute of Materials Science and Nanotechnology, Bilkent University, 06800 Ankara, Turkey \\ ${ }^{\mathrm{c}}$ Department of Physics, Marmara University, 34722 Istanbul, Turkey \\ ${ }^{\mathrm{d}}$ Department of Physics, Georgia State University, 30303 Atlanta, USA \\ ${ }^{\mathrm{e}}$ Department of Electrical and Electronics Engineering, Bilkent University, 06800 Ankara, Turkey
}

In this work the effect of Indium nitride ( $\mathrm{InN}$ ) nanoparticles (NPs) on the performance of a-Si:H solar cells has been investigated. The average $\mathrm{J}_{\mathrm{sc}}$ of InN NPs coated cells was found $6.76 \mathrm{~mA} / \mathrm{cm}^{2}$ which is $16.69 \%$ higher than the average $\mathrm{J}_{\text {sc }}$ of the reference cell which was $5.79 \mathrm{~mA} / \mathrm{cm}^{2}$. Average efficiency of InN NPs coated cells showed $14.16 \%$ increase from $3.32 \%$ to $3.79 \%$. Peak EQE has increased from $44.8 \%$ at $500 \mathrm{~nm}$ to $51.67 \%$ at $510 \mathrm{~nm}$ and peak IQE has increased from $51.70 \%$ at $510 \mathrm{~nm}$ to $68.38 \%$ at $500 \mathrm{~nm}$ for InN NPs coated cell. Further study shows that EQE change is larger between $510 \mathrm{~nm}-700 \mathrm{~nm}$ compared to IQE change indicting a surface scattering mechanism that reduces the reflectivity. However, between $400 \mathrm{~nm}-510 \mathrm{~nm}$ IQE change is larger than EQE change which indicates that energy downshifting mechanism is dominating. So overall performance enhancement can be attributed to the scattering and photoluminescence properties of InN NPs that enhances absorption inside a-Si:H solar cells.

\section{Introduction}

Thin film solar cells have gained a lot of attention due to the reduced material cost. However, decreasing the thickness also decreases the absorption of light and reduces the overall current the solar cell can generate. As a result, the use of such as nanoparticles to improve the performance of thin film solar cells is a topic of increased research and interest [1-7].

There are two approaches to this work: metal nanoparticles (Au or Ag) that supports localized surface plasmons (LSPs) to increase the optical absorption length or semiconductor nanoparticles that have photoluminescence property. Recently, semiconductor nanoparticles have also received great interest for enhancing the performance of optoelectronic device such as photodetectors and thin film solar cells [811]. Unlike metal nanoparticles, semiconductor nanoparticles can absorb higher energy photons and emit photons of lower energy. InN NPs can absorb ultra violet (UV) light that excites electron inside the nanoparticle from ground state to excited state. This excited state is unstable so electron lose energy via non-radiative relaxation and relax 
back to lower energy state. During this relaxation electron loses energy by the emission of vibrational energy. After that it further relaxes to ground state from lower energy state which involves emission of light. The energy of the emitted light is lower than the energy of the light being absorbed by InN NPs initially [12, 13].

A recent study of silicon nanoparticles in polycrystalline silicon solar cell has shown a power enhancement of $60 \%$ in the ultraviolet (UV)/blue range [8]. In the visible range, particles of $2.85 \mathrm{~nm}$ size showed $\sim 10 \%$ enhancement and particles of $1 \mathrm{~nm}$ size showed $\sim 3 \%$ enhancement [8]. This efficiency enhancement is mainly attributed to photoluminescence from UV/blue to visible/near infrared as a result of radiative recombination of photo-excited excitons. In this work, the effect of luminescent $16 \mathrm{~nm}$ InN NPs spin coated on top of thin film a-Si:H solar cells is studied.

\section{Experiment}

\section{$\underline{\text { Indium Nitride Nanoparticles Fabrication }}$}

The generation of InN NPs was carried out using a nanosecond pulsed ND:YLF laser operated at $527 \mathrm{~nm}$ with pulse duration of $100 \mathrm{~ns}$ and a pulse repetition rate of $1 \mathrm{kHz}$. The laser output power was $16 \mathrm{~W}$ with pulse energy of $16 \mathrm{~mJ}$. The laser beam was focused on High-Pressure Chemical Vapor Deposition (HPCVD) grown InN sample [14, 15] target containing $20 \mathrm{ml}$ pure ethanol using a plano-convex lens with a focal length of $50 \mathrm{~mm}$. The deposition process and optical properties of this HPCVD grown InN layer can be found elsewhere [16]. The height of liquid layer over the InN target was $5 \mathrm{~mm}$. The laser ablation was carried out for 5 minutes [14]. Figure 1 shows a transmission electron microscopy (TEM) image of the laser synthesized InN NPs in ethanol solution. InN NPs are spherical and are within $3.24 \mathrm{~nm}-36 \mathrm{~nm}$ size range with an average size of $16 \mathrm{~nm}$. The optical and spectroscopic properties of InN NPs along with their crystalline qualities are reported in detail elsewhere [14]. The Raman spectrum of InN NPs shows an $E_{2}$ peak at $496.76 \mathrm{~cm}^{-1}$ with a full width half maximum (FWHM) value of $5.36 \mathrm{~cm}^{-1}$ that is consistent with the experimental spectrum [14]. The optical absorption of InN NPs show absorption from $200 \mathrm{~nm}-1200 \mathrm{~nm}$ with prominent shoulders at $260 \mathrm{~nm}$, absorption edge starting around $500 \mathrm{~nm}$ [14]. Figure 2 shows the photoluminescence spectra of InN NPs under $250 \mathrm{~nm}$ and $300 \mathrm{~nm}$ excitation. For both excitations two peaks are visible, one in UV spectrum and the other one in visible spectrum.

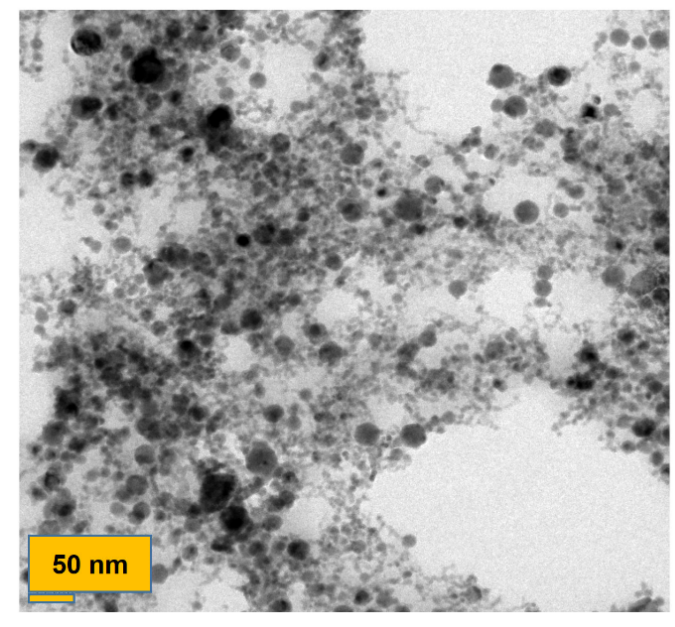

Figure 1. Transmission electron microscopy (TEM) image of laser synthesized InN NPs. 


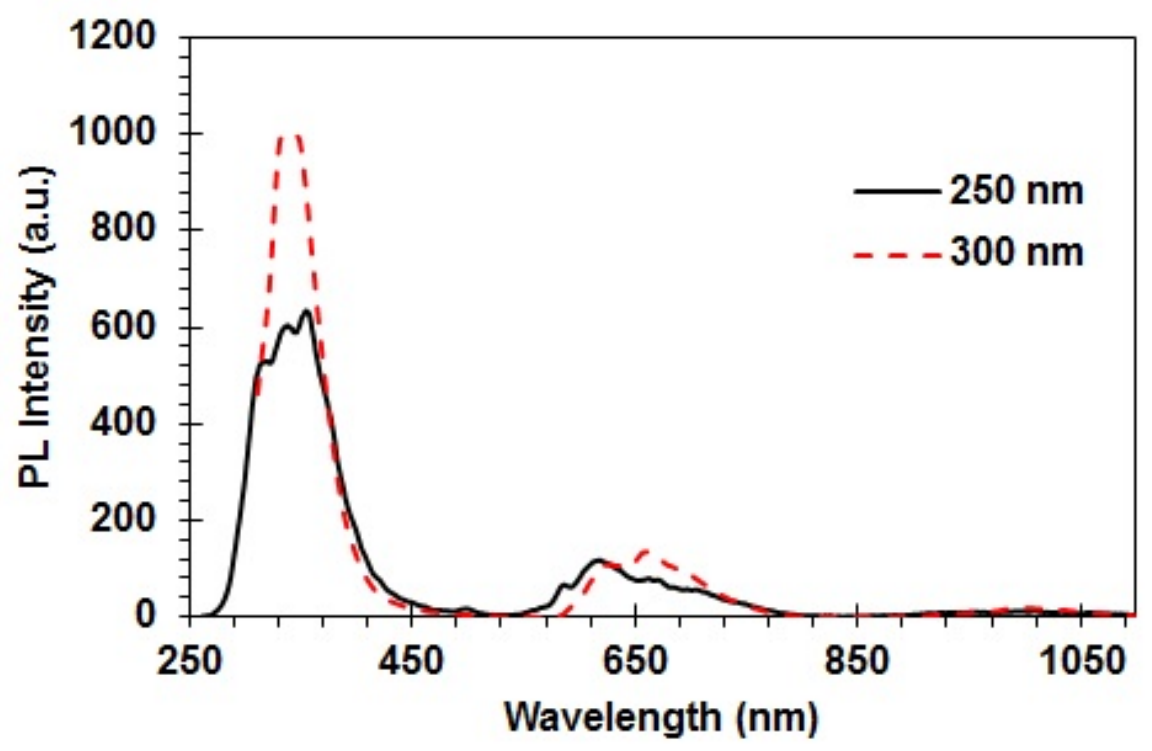

Figure 2. Photoluminescence spectra of $16 \mathrm{~nm} \mathrm{InN} \mathrm{NPs.} \mathrm{Excitation} \mathrm{at} 250 \mathrm{~nm}$ and 300 $\mathrm{nm}$ show picks in UV and visible spectrum.

\section{$\underline{\text { Solar Cell Structure and Fabrication }}$}

In order to study the effect of InN NPs on the performance of solar cells, a-Si:H solar cells were fabricated. Figure 3 shows cross section of the fabricated a-Si:H solar cells. 20 $\mathrm{nm}$ heavily doped p-type a-Si, $100 \mathrm{~nm}$ undoped a-Si, $20 \mathrm{~nm}$ heavily doped n-type a-Si and $80 \mathrm{~nm}$ Tin doped Indium Oxide (ITO) is grown on a $\mathrm{p}^{+}$type $\mathrm{Si}$ substrate. The $\mathrm{p}^{+}$type Si substrate serves as back contact and does not contribute significantly to the electron hole pair generation. The $\mathrm{n}^{+}, \mathrm{p}^{+}$and intrinsic layers were grown using the plasma enhanced chemical vapor deposition (PECVD) tool. ITO with a thickness of $80 \mathrm{~nm}$ was sputtered immediately afterwards to avoid interface defects using the RF sputtering tool [17-19]. More details of solar cell fabrication steps can be found in $[6,7,20,21]$. InN NPs in ethanol solution were then spin coated on top of ITO. Different spin coating recipes were studied and the optimized recipe turned out to be $2000 \mathrm{rpm}$ speed, $1000 \mathrm{rpm}$ acceleration and spinning time of 60s. After the NPs coating, metal evaporation was done to define the silver finger contacts. Silver was deposited using electron-beam evaporator tool and lift off technique was used to form the contacts. In this work, results presented are from solar cells of size $0.25 \mathrm{~cm} \times 0.25 \mathrm{~cm}$ unless otherwise stated. 


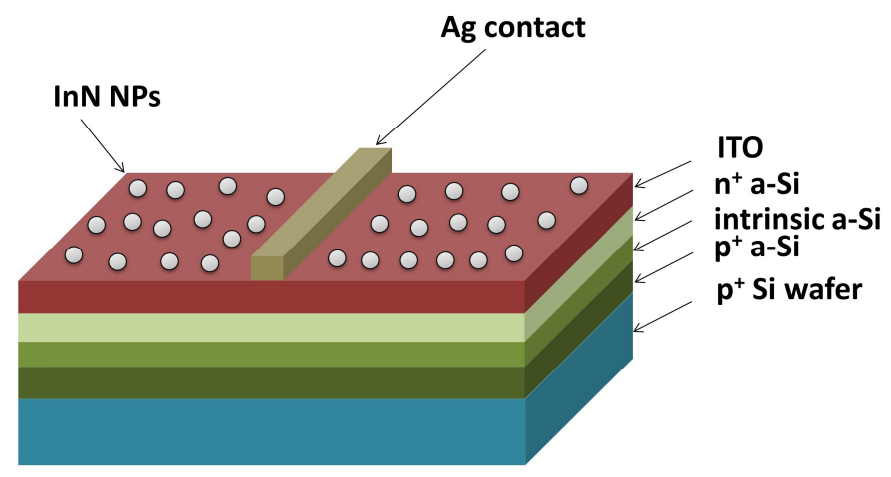

Figure 3. Layer stack of the fabricated $n-i-p$ a-Si:H solar cell with InN NPs deposited on the top surface (Figure not to scale).

\section{Experimental Results}

The enhancement was evaluated by comparing InN NPs coated cells with uncoated reference cells. For electrical (J-V under one sun i.e. AM1.5G) measurements 5 solar cells $(0.25 \mathrm{~cm} \times 0.25 \mathrm{~cm})$ were measured. Figure 4 shows the $\mathrm{J}-\mathrm{V}$ curves of the best performing solar cells (reference cell and cell coated with InN NPs). The $\mathrm{J}_{\mathrm{sc}}$ increases form $5.90 \mathrm{~mA} / \mathrm{cm}^{2}$ to $7.30 \mathrm{~mA} / \mathrm{cm}^{2}$. The efficiency also increases from $3.45 \%$ to $3.95 \%$ due to the increase in $\mathrm{J}_{\mathrm{sc}}$ for this cell. The $\mathrm{V}_{\mathrm{oc}}$ remains $0.89 \mathrm{~V}$ and does not change significantly with the InN NPs.

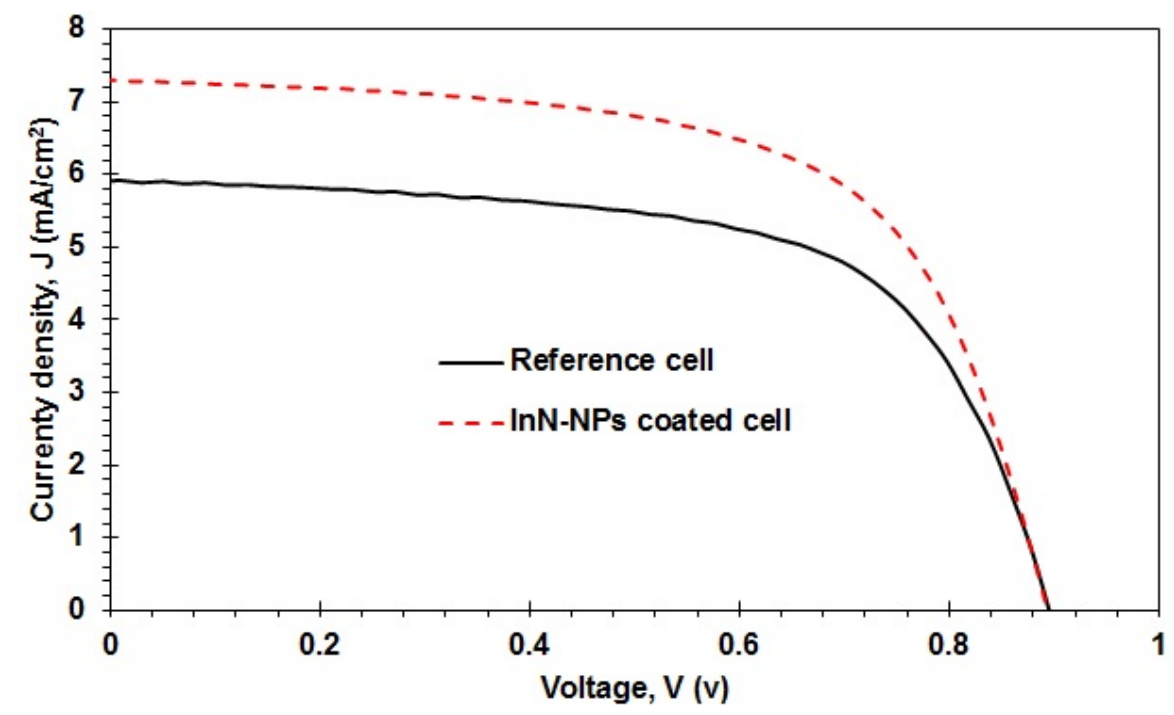

Figure 4. $\mathrm{J}-\mathrm{V}$ characteristics of $\mathrm{n}-\mathrm{i}-\mathrm{p}$ a-Si:H reference cell and cell with $\mathrm{InN}$ NPs under one sun i.e. AM1.5G.

For further study the effect of InN NPs on a-Si:H cell, external quantum efficiency (EQE), internal quantum efficiency (IQE) and reflectance of both reference cell and InN NPs coated cells were measured. From the EQE and reflectance of the cells the following formula is used to calculate IQE: 


$$
\mathrm{IQE}=\mathrm{EQE} /(1-\text { Reflectance })
$$

$\mathrm{EQE}, \mathrm{IQE}$ vs. wavelength is plotted in figure 5 for a-Si:H cells. Figure 5 shows that InN NPs coated cells have improved spectral response compared to reference cell. Peak EQE increases from $44.8 \%$ at $500 \mathrm{~nm}$ to $51.67 \%$ at $510 \mathrm{~nm}$ for InN NPs coated cells and peak IQE increases from $51.70 \%$ at $510 \mathrm{~nm}$ to $68.38 \%$ at $500 \mathrm{~nm}$. Figure 6 shows the reflectance of the InN NPs coated a-Si:H cells compared to reference cell. It shows a decrease in reflection from $500 \mathrm{~nm}$ onwards due to presence of InN NPs on top of the cells which means InN NPs are promoting light scattering. For a-Si:H cell, decrease in reflection is $26.14 \%$.

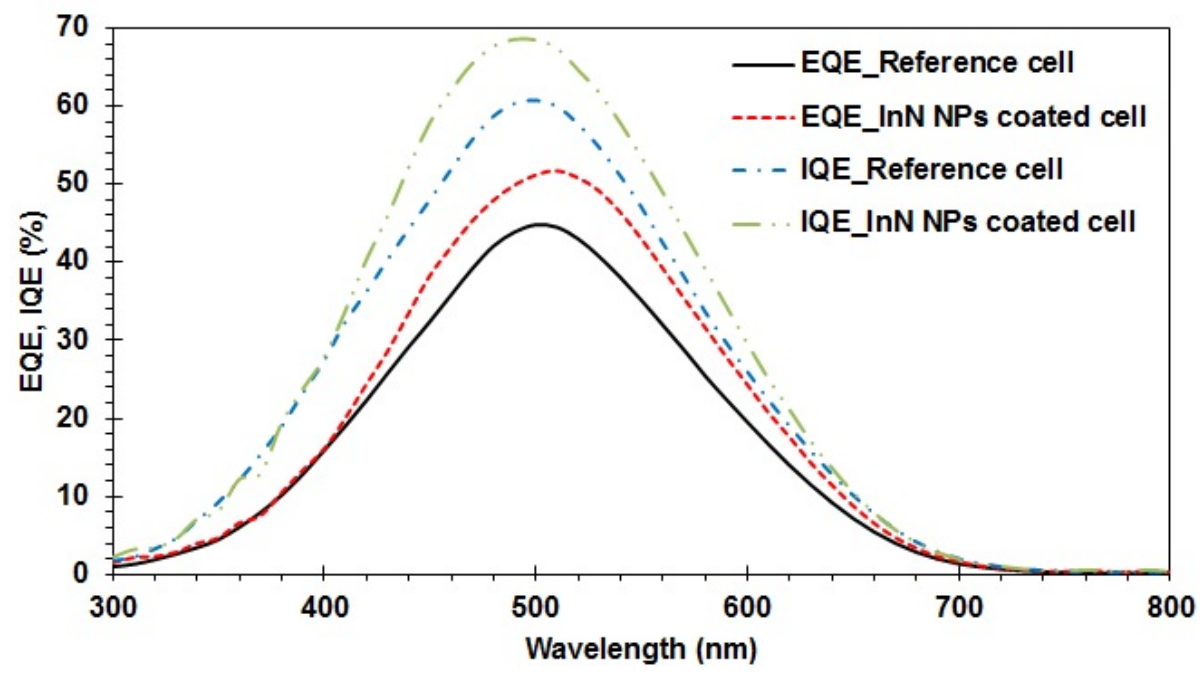

Figure 5. EQE and IQE of n-i-p a-Si:H reference cell and cells with InN NPs.

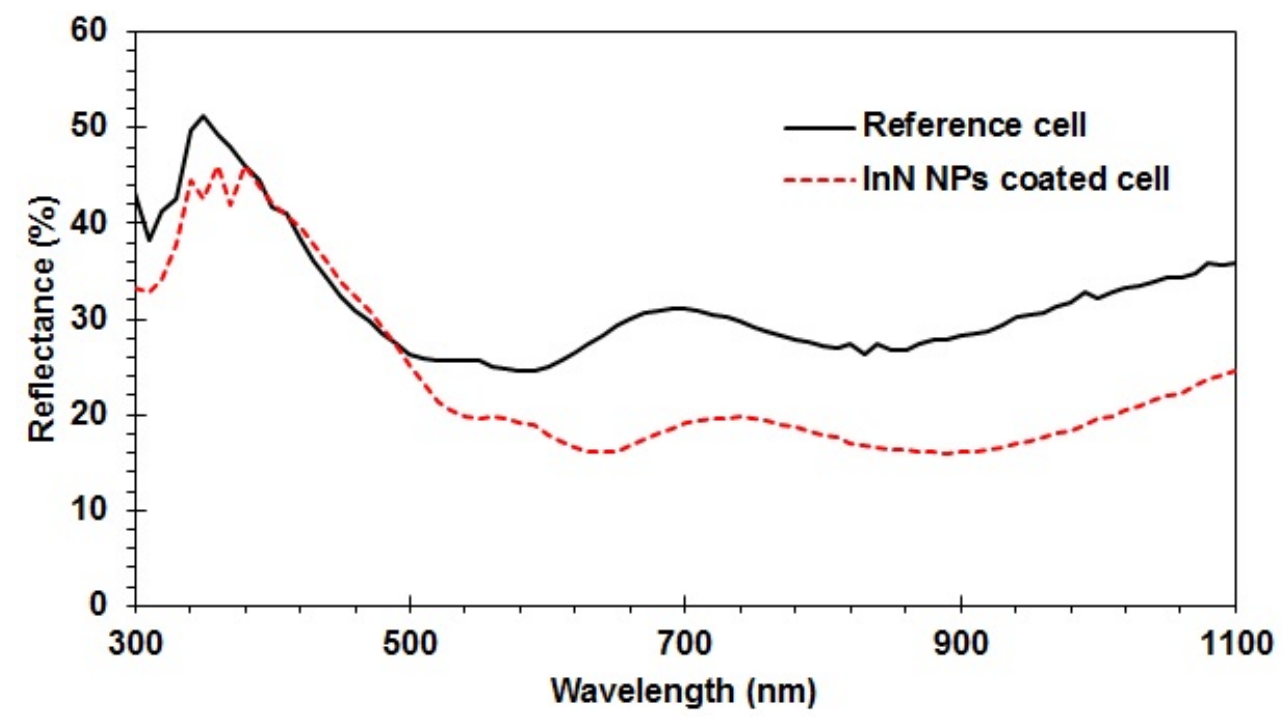

Figure 6. Reflectance of n-i-p a-Si:H reference cell and cells with InN NPs.

Table 1 summarizes main findings of this work, listing average $\mathrm{J}_{\mathrm{sc}}$, efficiency and fill factor of the reference and InN NPs coated solar cells. Average $\mathrm{J}_{\mathrm{sc}}$ of InN NPs coated 
cells is found to be $6.76 \mathrm{~mA} / \mathrm{cm}^{2}$ which is $16.69 \%$ higher than the reference cells which has an average $J_{\mathrm{sc}}$ of $5.79 \mathrm{~mA} / \mathrm{cm}^{2}$. And the average efficiency of InN NPs coated cells is $3.79 \%$, which is $14.16 \%$ higher than the average efficiency of the reference cells which is $3.32 \%$. The average fill factor of InN NPs coated cell improves from $62.97 \%$ to $63.10 \%$ as well.

Table 1. Summary of results

\begin{tabular}{cccc}
\hline & $\begin{array}{c}\text { Short Circuit current density } \\
\left(\mathbf{J}_{\text {sc }}\right)\end{array}$ & $\begin{array}{c}\text { Efficiency } \\
(\boldsymbol{\%})\end{array}$ & $\begin{array}{c}\text { Fill Factor } \\
(\boldsymbol{\%})\end{array}$ \\
\hline Reference cell & 5.79 & 3.32 & 62.97 \\
InN NPs coated cell & 6.76 & 3.79 & 63.10 \\
\hline
\end{tabular}

\section{Discussion}

In order to discuss the physics of the effect of the InN NPs on the solar cells the EQE and IQE are further analyzed. Figure 7 shows change in EQE and IQE vs. wavelength for a-Si:H cell.

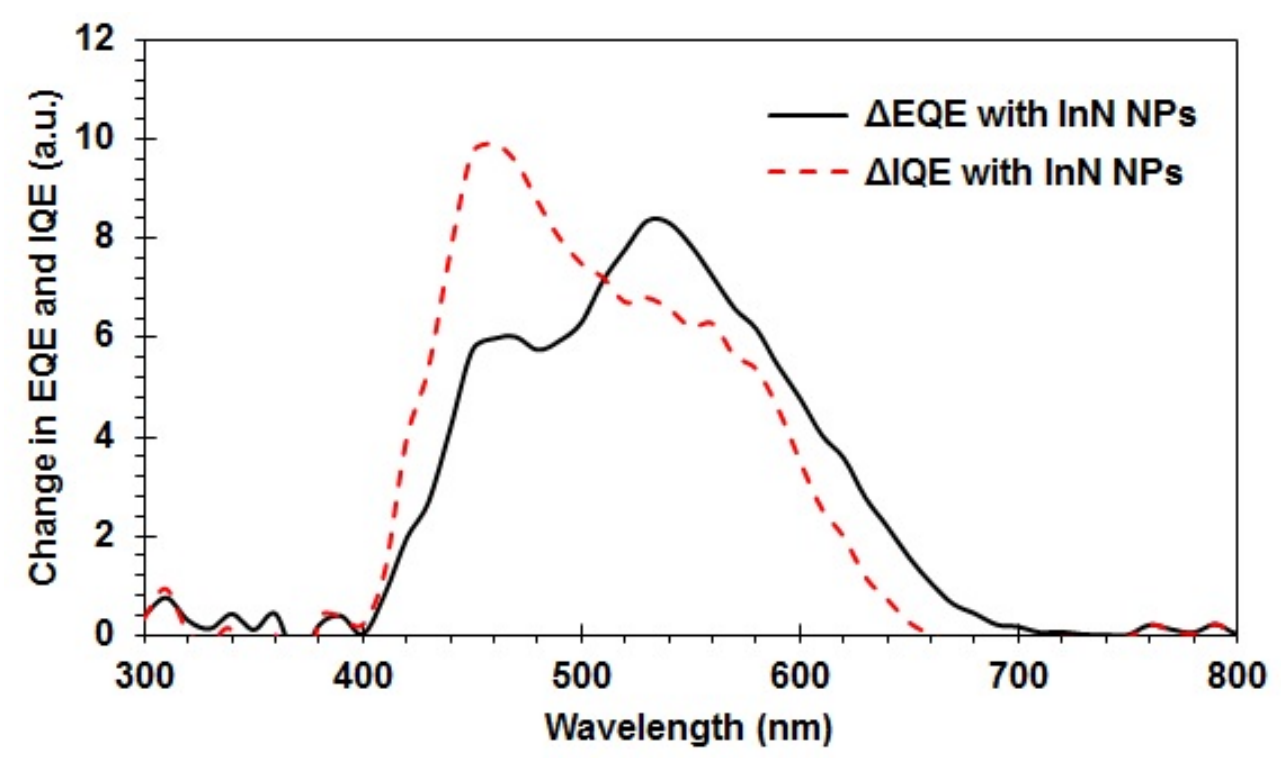

Figure 7. Change in external and internal quantum efficiency of n-i-p a-Si:H cells with InN NPs.

For InN NPs coated cell, figure 7 shows that $\mathrm{EQE}$ change is larger between $510 \mathrm{~nm}$ $700 \mathrm{~nm}$ compared to IQE change indicting a surface scattering mechanism that reduces reflectivity. Lower reflection of InN NPs coated cell from $500 \mathrm{~nm}$ onwards also supports this argument. However, from $400 \mathrm{~nm}-510 \mathrm{~nm}$ the IQE change is larger than EQE change which indicates an energy downshifting mechanism is dominating here. The InN NPs, with $0.7 \mathrm{eV}$ band gap, can absorb a high energy photon and downshift it to a lower energy photon that can be absorbed by a-Si material. The PL intensity measurement of the InN NPs also shows a high peak in the shorter wavelength region that supports our 
findings. Also, downshifting is effective in a-Si cell since the absorption depth indicates that $100 \mathrm{~nm}$ of a-Si material absorbs up to $540 \mathrm{~nm}$ of light $(\sim 2.30 \mathrm{eV})$. In figure 8 we have shown an energy level diagram of InN NPs coated a-Si:H cell.

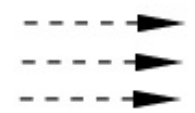

High energy photons

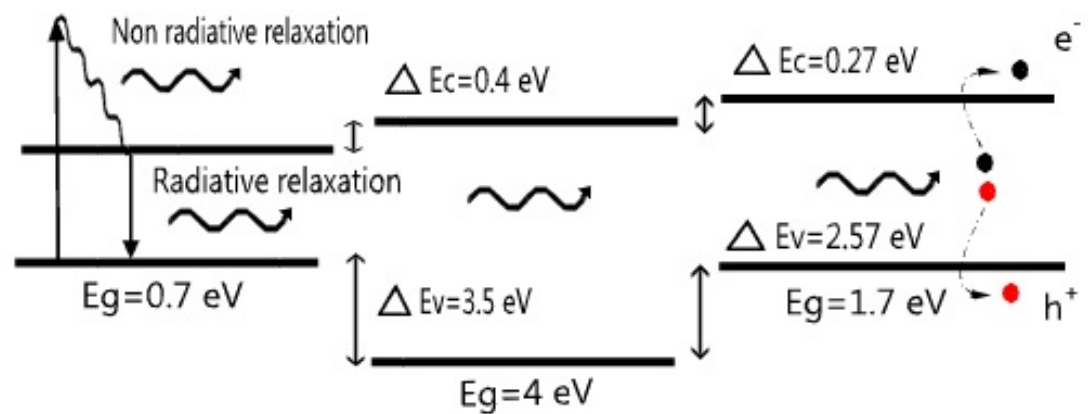

In N nanoparticle

ITO
a-Si material

Figure 8. Energy band diagram of InN NPs coated a-Si:H cell. High energy photons excite the electrons which is than undergo a non-radiative relaxation by emitting vibrational energy and radiative relaxation by emitting photons.

\section{Conclusion}

In summary, efficiency enhancement of thin-film a-Si:H solar cell using InN NPs is reported. Exploiting the scattering and photoluminescence properties of InN NPs short circuit current density and efficiency have been improved. Compared to the reference cells, average improvement of short circuit current density and efficiency of InN NPs coated cells are $16.69 \%$ and $14.16 \%$ respectively. The cells show higher change in IQE between $400 \mathrm{~nm}-510 \mathrm{~nm}$ which indicates that down conversion by InN NPs is the reason for performance enhancement in this region and higher change in EQE between $510 \mathrm{~nm}$ $700 \mathrm{~nm}$ indicates scattering of light by InN NPs is the reason for performance enhancement in this region. Finally, these results highlight a simple and promising use of nanotechnology for enhancement of future thin film solar cells.

\section{Acknowledgments}

We gratefully acknowledge financial support for this work provided by the Masdar Institute of Science and Technology. This work was partially supported by the Scientific and Technological Research Council of Turkey (TUBITAK) grant numbers 109E044, 112M004, 112E052 and 113M815. A.K.O. acknowledges support from the Turkish Academy of Sciences Distinguished Young Scientist Award (TUBA GEBIP). 


\section{References}

1. A. A. Harry, and P. Albert, Nature Materials, 9, 205 (2010).

2. H. Nasser, Z. M. Saleh, E. Özkol, M. Günoven, A. Bek, and R. Turan, Plasmonics, 8, 1485 (2013).

3. C. Eminian, F. J. Haug, O. Cubero, X. Niquille, and C. Ballif, Progress in Photovoltaics: Research and Applications, 19, 260 (2011).

4. K. Nakayama, K. Tanabe, and H. A. Atwater, Applied Physics Letters, 93, 121904 (2008).

5. O. Bamiduro, H. Mustafa, R. Mundle, R. Konda, and A. Pradhan, Applied physics letters, 90, 252108 (2007).

6. F. I. Chowdhury, A. Alnuaimi, K. Islam, and A. Nayfeh, Photovoltaic Specialists Conference, $\mathbf{4 0}^{\text {th }}, 2209$ (2014).

7. K. Islam, F. Chowdhury, A. Alnuaimi, and A. Nayfeh, Photovoltaic Specialists Conference, $\mathbf{4 0}^{\text {th }}, 3071$ (2014).

8. M. Stupca, M. Alsalhi, T. Al Saud, A. Almuhanna, and M. Nayfeh, Applied Physics Letters, 91, 063107 (2007).

9. S. Alkis, A. K. Okyay, and B. Ortaç, The Journal of Physical Chemistry C, 116, 3432 (2012).

10. S. Alkis, F. B. Oruç, B. Ortaç, A. C. Koşger, and A. K. Okyay, Journal of Optics, 14, 125001 (2012).

11. S. Alkis, T. Öztaş, L. Aygün, F. Bozkurt, A. Okyay, and B. Ortaç, Opt. Express, 20, 21815 (2012).

12. T. Feldtmann, L. Schneebeli, M. Kira, and S. W. Koch, Physical Review B, 73, 155319 (2006).

13. S. Chatterjee, C. Ell, S. Mosor, G. Khitrova, H. M. Gibbs, W. Hoyer, M. Kira, S. W. Koch, J. P. Prineas, and H. Stolz, Physical Review Letters 92, 067402 (2004).

14. S. Alkis, M. Alevli, S. Burzhuev, H. A. Vural, A. K. Okyay, and B. Ortaç, Journal of Nanoparticle Research, 14, 1 (2012).

15. N. El-Atab, F. Cimen, S. Alkis, B. Ortaç, M. Alevli, N. Dietz, A. K. Okyay, and A. Nayfeh, Applied Physics Letters, 104, 253106 (2014).

16. M. Buegler, M. Alevli, R. Atalay, G. Durkaya, I. Senevirathna, M. Jamil, I. Ferguson, and N. Dietz, International Conference on Solid State Lighting, $\mathbf{9}^{\text {th }}$, 742218 (2009).

17. ITO/a-Si deposited by MV Systems Inc.

18. A. Alnuaimi, A. Nayfeh, and V. Koldyaev, Journal of Applied Physics, 113, 044513 (2013).

19. A. Alnuaimi, K. Islam, and A. Nayfeh, Solar Energy, 98, 236 (2013).

20. S. A. Hadi, P. Hashemi, A. Nayfeh, and J. Hoyt, ECS Transactions, 41, 3 (2011).

21. S. A. Hadi, P. Hashemi, N. DiLello, E. Polyzoeva, A. Nayfeh, and J. L. Hoyt, Solar Energy, 103, 154 (2014). 